\title{
Promoting the Discipline: Rhetorical Studies of Science, Technology, and Medicine
}

\author{
Jeanne Fahnestock \\ Department of English, University of Maryland \\ College Park, MD USA
}

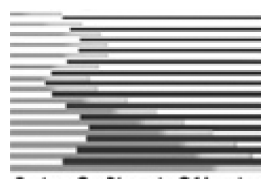

(a)

POROI

Poroi 9,1 (April 2013)

Our three position papers were charged with considering "invention processes" in the rhetoric of science, technology, and medicine (RSTM) and with reflecting on how our subdiscipline can be "more inventive within academic and public contexts" (ARST, 2012). Invention processes can be considered in two ways under this charge: in relation to the discourses of STM itself, or in relation to the discourses we produce when we study it, though this distinction can collapse when their differences become our differences. In what follows, I want to cover three broad issues raised by these position papers, discussing problems and possibilities for our discipline under each heading: (1) taxonomies of RSTM scholarship leading to questions about the nature of that scholarship and how it differs from what is produced in related disciplines; (2) difficulties and opportunities in addressing those in related fields or those who produce the discourse we study; and (3) areas for further work in RSTM.

\section{Taxonomies of RSTM Scholarship}

Professors Condit, Prelli, Depew, and Lyne offer us taxonomies of scholarship in the rhetoric of science, technology, and medicine, carving the beast at different joints. Focusing on invention strategies in the discourses studied (in the first of three parts of his paper), Prelli identifies two categories depending on whether the analyst attends to language and figurative invention or to the invention of arguments (stases, topoi, etc.). ${ }^{1}$

${ }^{1}$ A word of clarification is in order on the term "figures of thought," mentioned by both Prelli and Depew/Lyne in this issue. A bit of background: An early and highly influential taxonomy of figures of speech is found in Book IV of the Rhetorica ad Herennium, where there is a division of devices into figurae verborum and figurae sententiarum. Harry Caplan (1954) translates these phrases into figures of words and figures of thought. Figures of words includes all those devices that can be described in terms of syntax or word choice, or both. Later, these devices were called tropes and schemes. My work has focused on the schemes and on some devices of word choice like polyptoton and ploche, not on figures of thought. The sententiarum in figurae sententiarum is the genitive plural of sententia, a very difficult word to translate. It can mean thought, purpose, meaning or sentence, or something closer to a maxim or the 
Condit categorizes according to the purpose of the scholarly essay: theory building and improving science communication on the one hand, or indicting science as oppressive and too powerful on the other. Depew and Lyne provide a taxonomy of published scholarship according to subject matter or approach (major scientists, genres, fields, controversies, rhetorical invention, episodes, public use of scientific terms, language and figures, incommensurability, rhetoric and philosophy, rhetorical uses of expertise, medicine, materiality, risk, visual rhetoric, science and religion). Imagining these taxonomies as transparent overlays on an aerial photo of the terrain, each brings different aspects of the scholarship into prominence. But any one point could be located through all three layers. A graduate student in the field could, for example, place a project in all three taxonomies simultaneously: "Well, I am interested in studying methods of argumentation (Prelli) in the scientific controversy about the Flores Hobbit (Depew and Lyne) in order to contribute to rhetorical theory on studying controversies (Condit). Scholars need all three: a method, a subject matter, and an exigence defining their contribution.

These useful taxonomies do, however, conflate a potential distinction: that between studies of STM texts addressed within disciplines and those addressed to various publics. Condit (this issue) focuses on "academic essays addressing the public rhetorics of science and technology" but takes her concerns as applying generally to disciplinary discourse. Prelli and Depew and Lyne focus more on academic studies but also do not limit their taxonomies. Should there be a robust distinction here or not? Do we, for example, use or need different methods to study arguments made in the back pages of Science or Nature from those made in the front in the editorials, perspective pieces, review articles and news items? This potential difference will resurface in the following discussion. Among arguments for eliding differences is, first, the fact that earlier texts, while not uniformly accessible, nevertheless did not have professionally-niched audiences in mind (e.g., Lyell's Principles of Geology); second, some

point of a phrase; simply defining it as distinct from verborum, it names devices which cannot be pinned down linguistically. I have favored grouping these figures of thought as devices that perform certain high profile speech acts; there are other ways to categorize them. Furthermore, the schemes (antithesis, antimetabole, incrementum, etc.) are primarily of interest because they epitomize certain lines of argument. Hence this work also fits Prelli's second category concerned with analyzing argumentation with rhetorical theory. My contention is that some syntactic and lexical choices function as epitomes of certain lines of argument (as the most succinct/complete expression available). Because early modern scientists were thoroughly trained in the argument/figure connection, they readily brought certain "figures of argument" into their texts. For those who know the figures as thoroughly as they did, verbal expression can have heuristic power in directing the invention of applicable lines of argument and hence can affect physical/experimental practices. I certainly agree with Prelli then on the generative power of available forms. But, of course, nature need not cooperate. 
contemporary scientists continue to make their arguments to wider publics, sometimes to gain ground in a controversy (e.g., Adovasio and Page's The First Americans); and, third, controversies in Goodnight's "technical sphere" are often generated from or play out in the "public sphere" (e.g., laetrile as a cancer therapy) and, fourth, the preferred model for science/public interaction is collaboration minimizing differences, not one-way communication from the expert to the ignorant (e.g., Gross's 1994 article favoring a contextual over a deficit model of science communication). On the other hand, one reason for maintaining the difference comes from the easily conducted pedagogical experiment of having students with some rhetorical training work on an editorial on a science policy issue and then on an article from, say, Hippocampus or The Journal of Nonlinear Optical Physics and Materials. Of course, with or without a sharp separation between expert and non-expert discourse, attention to how differently sourced texts address differently informed audiences with different stakes in the material is surely one of the distinctions of a study labeled rhetorical. And that brings us to the next critical issue.

\section{What Makes STM Scholarship Rhetorical and Why Do It?}

Condit notes "a lack of sufficient collective-reflectiveness" (this issue) and issues a challenge for debate about the purposes of RSTM scholarship. But before we can debate the purpose of our enterprise perhaps we need to clarify its nature. There is good reason for asking this identity question yet again because, as noted in our position papers, many diverse academic fields attend to STM practices and discourse: not only the obvious big three - history, sociology, and philosophy-but also linguistics, literary studies, visual studies and art history, journalism, public relations, as well as applied fields like Public Health or Environmental Studies. What are our relations to these other subfields? How are we different? Alike? Prelli asks this question in the third part of his paper, especially in relation to "cross-disciplinary work with colleagues in other fields of STM studies." Imagine academics putting together an interdisciplinary team, some version of the "sustainability" group Prelli mentions. What would rhetoricians bring to the table? We think we know, but would scholars in other STM disciplines? As cases warrant, we study contexts like historians, audiences like sociologists, metaphor like literary scholars, language data like linguists, and argumentation practices like informal logicians or philosophers. We could simply add ourselves to a generalized science studies "metadiscipline" that deploys methods established in these fields depending on the project. But that would sacrifice our theoretical and historical grounding in a distinct discipline and falsify the history of these other disciplines in relation to rhetoric.

The "identity" question appeared in all three papers. Their common thread? RSTM is (1) distinctive for its attention to the choices that rhetors make against a background of possibilities, both in malleably defined contexts as well as at every possible level of formal analysis; and (2) different in pursuing the "why behind" and "what follows from" these choices. The choices (in modalities not limited to the verbal) constitute the "argument," the direct and indirect bids for intersubjective 
agreement. It is the background of possibilities for the choices, especially the formal possibilities, that is often invisible to non-rhetoricians.

Scientists and science writers are often aware of their options as they produce texts and visuals, but they lack rhetorical theory's analytical vocabulary for defining the possibilities at interconnected levels, including lines of argument, arrangement tactics, methods for characterizing the rhetorical situation and its players, and the deeper epistemically-orienting choices that come from larger patterns of selection and omission. Rhetorical theory is so overwhelmingly rich in options for analysis, and the actual material we can pay attention to is so limited by the space available in a typical scholarly study, that we always face our own radical selection dilemma.

The issue of what should/ should not count as rhetorical scholarship of scientific discourse has of course been visited before. Randy Harris discussed this boundary problem ably and thoroughly in 1997 and convincingly defined "rhetoric of science" as the "analysis of scientific discourse by scholars whose primary allegiances are to the guiding notions of rhetorical theory" (p. xxviii). Building on Harris, I (2007) acknowledged the same identity issue in a review essay written ten years later, but I included many cognate studies for the sake of coverage, taking a "metadisciplinary" approach. While convenient, such a broad view does not contribute to clarifying what a rhetorically informed study achieves. Depew and Lyne wonder, in effect, if rhetoric's contribution, our "primary allegiance," is clear to other scholars and "whether we rhetoricians of science have taken full advantage of the opening created by the broader discursive-social turn to articulate, deploy, and advertise our distinctive yet varied approach" (this issue). I think the simple answer is we have not. Yet how we define the nature and contribution of RSTM determines how we present ourselves to other disciplines in the academy, to the scientific community, and to the public. Surely ARST has a role in that presentation.

The relation of RSTM to other science studies disciplines has practical consequences for, among other reasons, the visibility of its scholarship, especially through literature-searching options. While books on science subjects with a rhetorical orientation make it through to the online database in the History of Science, Technology and Medicine, that resource does not cover work appearing in Rhetoric Society Quarterly or Rhetoric Review. The Communication \& Mass Media Complete database does cover these but not, it seems, Written Communication, and while the MLA Bibliography does cover the main rhetoric journals, it does not reference communication journals.

How aware are other academics of rhetorical approaches? Among practitioners in related disciplines, sociologists are certainly aware of rhetorical approaches; they may even subsume RSTM, considering rhetoric as the techne of constructionism. (Depew/Lyne (this issue) cite Latour's notice (albeit of a "despised" discipline.) The other two major disciplines studying science, history and philosophy, seem less likely to identify a distinct rhetorical approach or subdiscipline, though both also study scientific movements and discourse and even scientific argumentation, and the overlaps are considerable. 
Historians of science are certainly allied practitioners, yet they are often apparently unaware of rhetorical schlarship. ${ }^{2}$ They also routinely study the culture/science nexus and interpret discourse (as well as material artifacts and spaces), and they could use many of the categories in Depew and Lyne's taxonomy for their own work. Furthermore, if we define a rhetorical approach as involving an awareness of choices among possibilities, the historians of science have their apparently "rhetorical moments" as illustrated in the following passage from an article in Isis, the premier journal in the history of science. I use this very slight example to highlight the superficial similarities but perhaps deeper differences between a historical approach with "rhetorical instincts" and a rhetorical approach. The author, Alisha Rankin, had worked with an archive of sixteen thousand letters by and to Anna of Saxony, wife of the Elector, who was an effective medical practitioner and producer of distilled medicines and herbal remedies in sixteenth-century Germany. Rankin uses passages from the letters to argue for the existence of a network of noblewomen organized like artisans practicing a trade. To that end, she singles out the significance of Anna referring to Dorothea of Mansfeld in one of her letters as her lehrmeister, "a choice" that Rankin considers "striking in this setting" because it is an "ambiguous term that could mean 'teacher"but also invoked a master-apprentice relationship" and therefore "implied a hierarchy of knowledge" (Rankin, 2007, p. 37). In the article overall, this datum supports the case for artisan practices and therefore for "experimentalism" among this group of women and generally at this time in German courts. This attention to a particular word choice out of other possibilities (not mentioned) is fairly typical of the textual analysis in historical scholarship where language choices function as sign arguments for attitudes and themes. In other words, this piece of evidence is taken as a representation, not as a communication, though the details indicate that the letter accompanied samples of a distilled aqua vitae sent from Anna to Dorothea urging her to test the results and perhaps disclose more of her art. In short, rhetoricians would also note the more immediate context of one person communicating with another for a particular purpose. But I do not want to over-claim here. Representation and communication are two sides of the same interpretive coin, and it is easy to blend them by saying that what is represented is what is communicated. But decoding representations is the typical end point in historical and literary studies of science where texts are prized

${ }^{2}$ In a set of articles in Isis five years ago on the connections between the History and Philosophy of Science, Peter Galison (2008) listed ten problems that need addressing. Among these was Problem \#3, "Technologies of Argumentation." Galison called especially for more work in earlier periods, but suggested asking, "What are the tools, and procedures needed at a given time to construct an acceptable scientific argument?" Citing also the lack of an analytic scheme for understanding how visualization practices work, he wondered, "what is the toolkit of argumentation and demonstration-and what is its historical trajectory? (2008, p. 116). Galison seemed unaware of scholarship on the rhetorical/dialectical toolkit and its history. 
more for their signifying power-reading back to the culture that produced them - than for their communicative agency creating that culture.

Back to Condit's challenge. With RSTM as defined in our position papers, what is its purpose? Here the potential division into two streams surfaces again. If there is a difference in rhetorical studies of disciplinary STM discourse and rhetorical studies of STM discourse in public venues, then do we have different purposes and justifications? Focusing on science discourse in public venues to begin with, we could argue that these studies differ only in subject matter from rhetorical studies of political, religious, economic or any other public discourse. We use the same tools as rhetoricians in any other subdiscipline and just turn them on a different body of material. If the studies of those discourses are justified, then so are ours. So far as epistemic rather than public discourses of science are concerned, rhetorical studies of this material would be no different from studies of other knowledge-forming texts, though there are few such studies of the rhetoric of other disciplines. These "rhetoric as epistemic" studies examine the formation of bodies of knowledge in terms of a field's standards of argumentation, certainly a justification for the enterprise. My own view is that there is a historical reason for studying science rhetorically that stems from the origins of modern science in the sixteenth-century reform of the discourse arts, foregrounding rhetoric, and in the establishment of the conventions of scientific argument over the centuries by practitioners thoroughly trained in the art. But even without that rationale, scientists themselves would agree that their goal is to convince their peers, institutions, and the public about the validity and value of what they do, so studying scientific discourse as persuasion can be justified as the approach that most closely matches its nature.

Condit points out that some RSTM scholarship is critical if not outright antagonistic to the scientific enterprise and its institutions. Because of rhetoric's emphasis on argument and communication, and therefore on results, effects, consequences, and downstream repercussions, it is not surprising that scholarship on RSTM practices in public venues can turn critical and point out where choices have had or can have problematic effects. Scientists are also not above criticism, any more than any other elite, when they use their cultural authority to promote agendas outside their area of expertise and even outside what is warranted by what they know and the certainty with which they know it in their own fields. So criticism is certainly not off the table. I do, however, agree with Condit that a prima facie antagonism to science, technology, and medicine on the part of rhetorical scholars is inappropriate and unwarranted. Unfortunately, an impression that RSTM is exclusively deconstructive and antagonistic to science certainly exists. (More on this problem below.) Again, it is surely ARST's role to correct such misunderstandings.

\section{Addressing the Subject}

Some work in RSTM has found an audience among scientists, especially among those seeking help in communicating with the public or addressing granting agencies. Those who work in the rhetoric of 
medicine/health communication have a receptive audience among practitioners. Condit's advice to the genetics community, published in their journals, is a model here (e.g., 2001, 2007), and the expanding enterprise of teaching science and technical writing to undergraduate and graduate students has resulted in textbooks, courses and whole programs teaching the genres of science writing (e.g., Harmon \& Gross, 2010; Penrose \& Katz, 2009). Furthermore, there have been successful collaborative studies between rhetoricians and scientists, especially of the type where scientists allow access to their drafts and procedures or answer directed questions (e.g., Blakeslee, 2000; Charney, 1993). These studies tend, however, to be addressed to other RSTM scholars. Beyond that audience, there are impediments that make it difficult for rhetorical studies to get a hearing from those whose discourse we study.

\section{Using the " $\mathbf{R}$ " Word}

Anyone wanting to engage scientists under the banner "Rhetoric" has to be aware that in Science and Nature, publications widely read by scientists and allied professionals, the term is overwhelmingly used in negative contexts. Indeed a search of the term rhetoric in the online Science archive yields 1158 uses, and a sampling of the quotations provided suggests that the overwhelming majority are pejorative, from an 1883 lament that competitive examinations for professorships "too often give the showy qualities of rhetoric and smartness the preference over solid merit as proved by original research" ("Present State," 1883), to the most recent in a September 2012 complaint about "the torrent of campaign rhetoric" that obscures the science policies of the candidates (Malakoff, 2012, p. 337; the very earliest uses in 1881 refer to chairs of rhetoric in neutral ways). In a similar search of Nature, a sampling of the resulting 610 instances (1205 including its other holdings) yields the same profile of negative usage. The typical immediate context for these appearances of rhetoric is an article reporting on news of interest to scientists. Overall, the use of the word rhetoric in Science and Nature trends with its use at large as a term with negative associations, as evidenced by a search in the Corpus of Contemporary American English (COCA) where rhetoric collocates with political, despite, reality, harsh, fiery and mere (COCA). None of these details will surprise this audience, but they are worth remembering. The response, however, should not be to drop the "R" word from our scholarship and advocacy.

Rare bright spots have occurred with the reviews of work by Gross and Harmon in Nature (Shapin, 2007) and by Leah Ceccarelli in Science (Rorty, 2001; and I may be focusing too narrowly on these two international weeklies.) Still, consider that Stephen Shapin's review of Gross and Harmon's 2007 anthology The Scientific Literature: A Guided Tour, titled "The Art of Persuasion," is followed by the subtitle, "Surprisingly, the rhetoric of the literary artist still has a place in persuasive scientific texts" (2007, p. 751). Shapin also observes that "There are now many historical and sociological studies of scientific communication" (p. 751), but evidently in his view no rhetorical ones. In Richard Rorty's (2001) review of Ceccarelli's Shaping Science with Rhetoric, there is actually an endorsement of the fledging field of the 
"rhetoric of science," but as far as Science readers would know since then, the fledgling apparently died in the nest. 33

\section{Parallel Discourses: A Digression}

To add to the impediments of talking about rhetoric to professional communities who, in our terms, produce it, is the fact that there is now a parallel discourse under construction in evolutionary psychology/biology and in the neurosciences covering concepts long identified in rhetorical theory. Consider, for example, recent changes in the discourse of evolutionary biology, Depew and Lyne's territory (e.g., Depew, 2010; Lyne $\&$ Howe, 1990). For decades it has been a goal in evolutionary biology/psychology (once called sociobiology) to account for how evolution by natural selection could favor cooperation or altruism in any species, including humans, since any organism not acting in its own best interests seems liable to be selected out of existence. The standard answer, popularized by Richard Dawkins, has been kin selection formalized in Hamilton's law. Cooperative or altruistic actions are only favored to the degree they are exercised toward offspring or siblings in ways mathematically proportional to the degree of gene sharing. (Here is where those canonical examples that Depew and Lyne talk about came in handy.) But in the past few years, kin selection or "inclusive fitness" has been demoted in favor of a more complex view of the selective pressures favoring cooperative behavior and, in the case of humans, attention has shifted to gene-culture co-evolution. Even E.O. Wilson (2012) now recants his former faith in kin selection and declares his conversion in his most recent work, The Social Conquest of Earth. The current lead spokesperson for this new view is Martin Nowak (2012). In a campaign conducted in disciplinary journals, in Science, in Scientific American and a quasi-popular book (short title Super Cooperators), Nowak promotes a view of five selective pressures favoring cooperation: spatial selection, kin selection, direct reciprocity, indirect reciprocity, and group selection (2006; he can also be credited with coining an outrageous agnominatio which nevertheless perfectly epitomizes his case for an alternate view fit to displace a familiar one: "Life therefore is not just a struggle for survival-it is also, one might say, a snuggle for survival" [2012, p. 36]). Direct reciprocity is the "tit for tat" that one often sees in game theoretical modeling of selection strategies: individuals exchange favors one on one. But, as Nowak explains, in "indirect reciprocity, one individual decides to aid another based not on reciprocal benefit but on the needy individual's reputation. Those who have a reputation for assisting others who fall on hard times might even find themselves on the receiving end of good will from strangers" (2012, p. 38; see also Wilson, 2012, 249). It seems then

3 There have been other "sightings" in Science of the term "rhetoric of science" since then referencing a discipline, including from science writer Steve Olsen, reviewing books on the Intelligent Design debate (Olsen, 2004), and from Miriam Solomon (2008) reviewing Susan Haack's (2003) Defending Science. These are single mentions in the context of criticism. 
that individuals can accrue benefits on the basis of what other people think about them. Sound familiar?

Again, in "Adapted to Culture," the British evolutionary biologist Mark Pagel (2012) takes an essentially rhetorically-friendly view of language as a "social technology" that evolved because it was needed. He also lists humans' ability to discern the thoughts and intentions of others (theory of mind) as kick-starting the evolution of cooperation in human cultures, along with language, but he does not really put these two factors together. Yet, the notion of using language to secure cooperation by taking the listener's views into account (aka rhetoric) seems just a step away. A similar rhetoric-compatible understanding of language is on display in a recent study of a tribe of "hunter gatherers" who presumably provide access to earlier patterns of human social organization. Here the authors note that the cooperation they observed had perhaps two explanations: one, that cooperators who form ties to one another leave defectors out in the cold; "Another is that people may influence the cooperative behaviour of their networks" (Apicella, Marlowe, and Fowler, et al., 2012). Of course, by "influence," evolutionary biologists mean something less than "full court" persuasion to belief or action, and they are usually only concerned with modeling influence in networks (i.e. pairwise relations more easily mapped mathematically), though "influence" can include person-to-person advocacy in a political campaign (Nickerson, 2008). Nevertheless, the rediscovery of persuasion in studies of "hunter-gatherers" is obvious. As these examples from the discourse of evolutionary biology show, terms like reputation and influence have cognate meanings to concepts rhetoricians are familiar with, creating potential interference with rhetorically-grounded approaches.

On the positive side of crossover, rhetoricians owe a debt of gratitude to the neurosciences and their able researchers/ rhetorical accommodators, the most well known being Antonio Damasio (1994) and Joseph LeDoux (2002), who have justified the place of emotion/pathos in human reasoning and "decision making," where it has always been in rhetorical theory (see Condit, 2011). But at the same time one comes across an article in Nature concluding that "People's grasp of scientific debates can improve if communicators build on the fact that cultural values influence what and whom we believe," an insight that apparently escaped "prevailing theories of science communication" (Kahan, 2010). I confess to a kind of amazement when I encounter evidence of these reconstructions of the starting points of rhetorical theory. This parallel discourse is the context, and a potential impediment, to introducing a rhetorical vocabulary for similar ideas. But perhaps it should be seen instead as an opportunity for the "transilient perspective" (Condit \& Railsback, 2005) that Condit calls for, tracing the "continuities and discontinuities among the humanities, natural sciences, and social sciences" (this issue). 


\section{Gratitude Unlikely}

In their discussion of "Rhetoric as Process," Perelman and OlbrechtsTyteca point out the inevitable devaluing effect of identifying the techniques of persuasion: "the mere presence of schemes of argument and techniques of persuasion that are theoretically transferable to other discourses may be enough to suggest the charge of device" (1969, p. 452). There is, in other words, an innate criticism in the descriptive rhetorical analysis of any text, especially texts in the sciences, which are supposedly dictated by the authors' findings (even though all acknowledge that their content has been molded into the form demanded by the genre of the science article). An apparently critical stance to the object of analysis therefore seems an inevitable consequence of the simple act of identifying techne, and the subject of such an analysis is not likely to be grateful. The identification of device in rhetorical terms can even provoke the defensive response that the analyst is just re-labeling the obvious, something not unlike my reaction to the parallel discourse noted above.

The circumstances complicating how rhetorical scholars address the larger scientific community come then, in part, from the negative associations lingering in popular usage of the term rhetoric, from the presence in scientific publications of a parallel discourse that discusses issues long familiar in rhetorical theory, and from the inevitably critical impression that can accompany any identification of methods typically invisible to their user. There are perhaps strategies for overcoming these impediments, and ARST should have a role in finding them.

\section{Future Work}

Despite the "Rodney Dangerfield" overtones of the previous section, like any subdiscipline, RSTM has an audience, and the most important one, the one that sets the standards: its own practitioners. The purpose, or exigence, of any particular study has to be argued into place by its authors in the opening of that study, and previous work often provides exigence for further work. Judging by publications and programs, the field is expanding and will expand in the future. Our three position papers all address the important issue of "inventing" the future for the RSTM, and Depew and Lyne remind us that the potential subject matter is vast. What are recommended directions? Where are changes in what we study taking us? The following brief list suggests some possibilities.

1. Condit points out the English language and Euro-American bias in RSTM scholarship and encourages a more global/ international perspective.

No one is likely to disagree with that call; this organization took the term "American" out of its title in 2006. But I would like to offer some reservations. Contemporary science is largely-not exclusively, but largely-a European enterprise in its origins, and currently English is the lingua franca of scientific communication around the world. Science has an international workforce, and a lab in Finland may have an Argentinian 
director, a Taiwanese researcher, and a German postdoc who all communicate with each another in English. And though there is no reason to suppose this dominance will continue, currently approximately 90\% of scientific periodicals are published in English (Hamel, 2008). Depending on how Whorfian one's assumptions are, this English bias does or does not make a difference in the resulting knowledge argued into place (see Swales, 1997), but it does not seem likely that Euler's constant $e$ changes its value on different continents or that the role of the pancreas in diabetes is different in Pakistan and the US.

However, communicating STM issues and policies to larger publics is something else, and the cultural and linguistic differences can be enormous. HIV-prevention campaigns across the globe, for example, have to be tailored to cultural norms. For this kind of international work, there has to be collaboration with people in other countries with the necessary linguistic and social expertise. Knowing another language is not enough. The prospects for international collaborative work are becoming more likely with the creation of the Rhetoric Society of Europe and the opening of the first Department of Rhetoric and Communication in China at Beihang University in 2011. Of course there is also the problem of whether the rhetorical theory we practice, albeit in international contexts, is itself Euro-American and if it is not, need not or should not be, we are back with the "nature of" question.

2. I would strongly underscore Prelli's point, one I have also made elsewhere, that more work needs to be done on the Visual Rhetoric of Science.

Here Alan Gross has once again pointed the way in articles and in his forthcoming book with Joseph Harmon, What One Picture is Worth. This need is driven by the fact that, as Gross has amply pointed out, scientific discourse (and also that in technology and medicine) is and has been historically characterized by its use of visuals. All the disciplines studying STM discourse are aware of this need. Among historians, for example, M. Norton Wise (2006) introduced a "Focus" section in Isis on "Science and Visual Culture," complaining that historians had paid little attention to images and their epistemological significance and calling for a basic survey of image-making modes and a "need to understand images as arguments" (p. 75). A model for explaining how visuals work as arguments can be found in Prelli's (2006) analysis of the U.S. and Canadian maps and graphics used in a legal dispute over fishing banks in the Atlantic.

There has already been significant work on visuals used in science from every possible disciplinary angle, and of course Visual Rhetoric is a major field in Communication Studies (a point not noted in Wise's 2006 Focus articles on "Science and Visual Culture"). There is a growing body of rhetorical theorizing on and empirical studies of how images persuade, what kinds of arguments they embody or assist, and how they reinforce or are reinforced by verbal arguments. Nor are rhetoricians the only ones on this quest; informal logicians have been debating how pictures argue in their very tight sense of the word argue for almost twenty years (see 
Aspeitia, 2012). But overall visual rhetoric (or variously visual communication or visual studies) lacks an overarching theory uniting the work of semioticians, of art and graphics historians, of practitioners like Tufte and Frankel, and of argumentation theorists or rhetoricians with their focus on persuasion. There has yet to be a single treatise with the explanatory power for visual rhetoric comparable to that of Perelman and Olbrechts-Tyteca's New Rhetoric. Furthermore, general theories of visual persuasion will have to be adapted to visualization in the sciences where there are unique problems posed by instrument-mediated visualization and the evolution of practices like "visual abstracts."

3. Certainly other topics could be added to a wish list of areas for future work. All of Depew and Lyne's categories are underserved. I would also suggest the following:

a. There should be more studies of the rhetoric of technology, the applied science that drives the economy.

Bazerman's (2002) The Languages of Edison's Light is exemplary but isolated. A seminal work in technology studies like David Nye's (1999) American Technological Sublime suggests how many potential subjects await rhetorical treatment.

b. Scholars in digital studies have noted the seismic shift to the Internet as a medium for scientific collaboration and communication.

More than just new accessibility (e.g., PubMed with its special filters and translators accessing MEDLINE and other databases), the web has prompted new solely online publications like PLOS ONE (formerly PLoS ONE) and the Frontiers journals, starting with Frontiers in Neuroscience. Even print journals are changing their content, and the nature of their arguments, with the new affordance of links to supporting material on line. Whenever the medium changes, the rhetorical affordances change, and these online journals with their faster rates of reviewing and publishing and their bibliometric protocols are altering the interactivity of research fields and the nature of the impact factor from citation to viewing/downloading. However, this new medium has yet to change the need for "journal" publication as an authorizing warrant for the credibility of a scientific research report, though it is now dead easy to create ersatz journals, plausible Internet portals that are money-making schemes to collect fees for publication. Jeffrey Beall (2012), a librarian at the University of Colorado Denver, reports on his blog "Scholarly Open Access" of the instant creation of the online International Journal of Engineering Sciences and Research Technology with seven bogus previous issues, possibly generated, Beall speculates, by using SCIgen, an automatic Computer Science paper generator (October 18, 2012). Given the ease of fabrication on the Internet, and the current explosion of retractions based on fraud and plagiarism facilitated by the Internet, it is clear that this medium is affecting scientific communication in ways that 
have yet to play out. RSTM should be active in examining and assessing the shift to an Internet-enabled knowledge economy.

\section{Conclusion}

There will and should occur, as in any active field, new perspectives and combinations of methods and subject matter. Ideally, there should be more specifically rhetorical histories of scientific discourse. By "rhetorical histories," I mean tracings of the rise, change, and occasional fall of argmentative practices, devices, methods, techniques, or of the commonplaces of STM that Prelli mentions. Within fields, these can be histories of certain special topoi, though rhetorical theory also looks at devices that cross content areas. This last category strikes me as especially important to the visibility of RSTM as a unique discipline, and there should be creative combinations here that have never appeared before. Such scholarship of the future is likely to come from a new generation who have credentialed training in both rhetoric and in a scientific specialty. Again, ARST should have a hand in promoting this invention, as it has in eliciting the three position papers that set an agenda for constructive debate.

\section{References}

Adovasio, J. M., \& Page, J. (2002). The first Americans: In pursuit of archaeology's greatest mystery. New York: Random House.

Apicella, C. L., Marlowe, F. W., Fowler, J. H., \& Christakis, N. A. (2012). Social networks and cooperation in hunter-gatherers. Nature, 481(26), 497-501.

ARST. (2012). Inventing the future: ARST vicentennial preconference. Accessed April 3, 2013. http://www.arstvicentennial.weebly.com

Aspeitia, A. A. B. (2012). Words and images in argumentation. Argumentation, 26, 355-368.

Bazerman, C. (2002). The languages of Edison's light. Cambridge, MA: MIT Press.

Beall, J. (2012, October 18). New journal publishes seven issues of bogus articles to appear successful. [Web log comment]. Accessed April 23, 2013. http://scholarlyoa.com/2012/10/18/bogus-articles/

Blakeslee, A. M. (2000). Interacting with audiences: Social influences on the production of scientific writing. Mahwah, NJ: Lawrence Erlbaum.

Caplan, H. (Trans.). (1954). [Cicero]: Rhetorica ad herennium. Cambridge, MA: Harvard University Press.

Charney, D. (1993). A study in rhetorical reading: How evolutionists read The Spandrels of San Marco. In J. Selzer (Ed.), Understanding scientific prose (pp. 203-231). Madison, WI: University of Wisconsin Press.

Condit, C. (2001). What is 'public opinion' about genetics? Nature Reviews Genetics, 2, 811- 815. 
----. (2007). How geneticists can help reporters to get their story right. Nature Reviews Genetics, 8, 815-820.

----. (2011). Pathos, for us. Accessed April 8, 2013. http://ccondit.myweb.uga.edu/attic/files/Chs1\&2PathosCondit.pdf

Condit, C. M. \& Railsback, L. B. (2005). The transilience project. Accessed March 10, 2013. http://www.gly.uga.edu/railsback/Transilience/Transilience.html

Damasio, A. (1994). Descartes' error: Emotion, reason and the human brain. New York: G.P. Putnam.

Depew, D. J. (2010). Is evolutionary biology infected with invalid teleological reasoning? Invited review essay of John Reiss, Retiring Darwin's Watchmaker. Philosophy and Theory in Biology, 2(105). Accessed April 8, 2013. http://works.bepress.com/david depew/58

Fahnestock, J. (2008). The rhetoric of the natural sciences. In A. Lundsford, K. H. Wilson, \& R. A. Eberly (Eds.), The SAGE handbook of rhetorical studies (pp. 175-196). Thousand Oaks, CA: Sage.

"Finding a good example." (2007). Science, 315, 909.

Galison, P. (2008). Tens problems in history and philosophy of science. Isis, 99(1), 111-124.

Gross, A. (1994). The roles of rhetoric in the public understanding of science. Public Understanding of Science, 3, 3-23.

Haack, S. (2003). Defending science-Within reason. Amherst, NY: Prometheus Books.

Hamel, R. E. (2008). The dominance of English in the international scientific periodical literature and the future of language use in science. In A. Carli \& U. Ammon (Eds.), Linguistic inequality in scientific communication today. AILA Review, 20, 53-71.

Harmon, J. H., \& Gross, A. G. (Eds). (2007). The scientific literature: A guided tour. Chicago, IL: University of Chicago Press.

----. (2010). The craft of scientific communication. Chicago, IL: University of Chicago Press.

Harris, R. A. (Ed.). (1997). Introduction. Landmark essays in the rhetoric of science: Case studies (pp. xi-xlv). Mahwah, NJ: Lawrence Erlbaum.

Kahan, D. (2010). Fixing the communications failure. Nature, 463, 296297.

LeDoux, J. (2002). Synaptic self: How our brains become who we are. New York: Viking.

Lyell, C. (1830). Principles of Geology 1. London, UK: John Murray.

Lyne, J. \& Howe, H. (1990). Rhetorics of expertise: E.O. Wilson and sociobiology. Quarterly Journal of Speech, 76, 134-151.

Malakoff, D. (2012, September 14). In a torrent of campaign rhetoric, hints of science policy. Science, 337, 1284-1285. 
Nickerson, D.W. (2008). Is voting contagious? Evidence from two field experiments. American Political Science Review, 102, 49-57.

Nowak, M. A. (2006, December 8). Five rules for the evolution of cooperation. Science, 314, 1560-1563.

----. (2012, July 19). Why we help. Scientific American, 36-39.

Nye, D. (1999). American technological sublime. Cambridge, MA: MIT Press.

Olson, S. (2004). Evolution and creationism: Shapes of a wedge. Science, $304,825-826$.

Pagel, M. (2012). Adapted to culture. Nature, 482, 297-299.

Penrose, N., \& Katz, S. B. (2009). Writing in the sciences: exploring conventions of scientific discourse (3rd ed.). White Plains, NY: Longman/Pearson.

Perelman, C. \& Olbrechts-Tyteca, L. (1969). The new rhetoric: A treatise on Argumentation. (J. Wilkinson \& P. Weaver, Trans.). Notre Dame, IN: University of Notre Dame Press.

Prelli, L. J. (2006). Visualizing a bounded sea: A case study in rhetorical taxis. In L. J. Prelli (Ed.), Rhetorics of display (pp. 90-120). Columbia, SC: University of South Carolina Press.

“Present state of science in Brazil." (1883, March 30). Science, 1, 211-214.

Rankin, A. (2007). Becoming an expert practitioner: Court experimentalism and the medical skills of Anna of Saxony (15321585). Isis, 98(1), 23-53.

Rorty, R. (2001). Studied ambiguity: Review of L. Cecarelli, Shaping Science with Rhetoric. Science, 293, 2399-2400.

Solomon, M. (2003, July 2). Messing with common sense. Science, 305, 44-45.

Shapin, S. (2007). The art of persuasion: Review of The Scientific Literature: A Guided Tour, edited by J. E. Harmon \& A. G. Gross. Nature, 448, 751-752.

Swales, J. M. (1997). English as tyrannosaurus rex. World Englishes, 16(3), 373-382.

Wilson, E. O. (2012). The social conquest of the earth. New York: W.W. Norton.

Wise, M. N. (2006). Making visible. Isis, 97(1), 75-82. 